\title{
La sociología de los partidos políticos bajo el prisma de la derecha francesa*
}

\author{
Julien Fretel**
}

\begin{abstract}
Resumen
En Francia, los partidos políticos de derecha han sido desdeñados por la ciencia política, por varias razones. Una de éstas se debe a la duradera supremacía del modelo de Maurice Duverger basado en la oposición entre partidos de cuadros y partidos de masas. Por ende, resulta valioso para la teoría de los partidos políticos estudiar aquellas formaciones políticas que suelen ser consideradas como partidos por defecto o partidos sin militantes para permitir la evolución de los paradigmas, las teorías y los conceptos referidos a las organizaciones políticas. En este sentido, el artículo propone tomar a la derecha no gaullista (UDF) como campo de estudio.
\end{abstract}

Palabras clave: Unión para la Democracia Francesa - derecha francesa - institución partidaria - dirigentes centristas - militancia.

\begin{abstract}
In France, right wing political parties have been neglected by political science. Reasons are various. One of them results from the long-lasting supremacy of Maurice Duverger model based on cadre party versus mass party. However, it is worth for political parties theory to study what used to be considered as parties by default or parties without active members. This enables us to make evolve paradigms, as well as theories and concepts regarding political organisations. Therefore, this article aims at considering the French "not gaulliste" right wing (UDF) as a field of study.
\end{abstract}

Keywords: Union for French Democracy - French right wing - partisan institution - centrist leaders - militancy.

* Traducido por Ana Perrin-Heredia. Este trabajo se enmarca en el Proyecto de Investigación ECOS-CONICYT C05H01 y constituye una versión retrabajada de una ponencia presentada en el taller sobre "La derecha" organizado por Lucie Bargel, Stéphanie Dechezelle y Anne-Sophie Petitfils con ocasión del Congreso de la Asociación Francesa de Ciencia Política. Este texto reúne esencialmente un conjunto de argumentos desarrollados en nuestra tesis doctoral y en varios artículos ya publicados. Agradecemos por sus comentarios y sugerencias a las organizadoras, a los participantes y a quienes discutieron los trabajos presentados, en particular a Florence Haegel y Jean-Louis Briquet.

** Profesor de Ciencia Política de la Universidad Picardie Jules Verne (Amiens) y de Sciences Po Lille. Es miembro del Centro Universitario de Investigaciones sobre la Acción Pública y lo Político (CURAPP) UMR CNRS 6054. Correo electrónico: freteljulien@yahoo.fr 
Durante mucho tiempo, la sociología de los partidos políticos en general, y la de la militancia partidista en particular, no tomó en cuenta los partidos de derecha. En lo que respecta a las formaciones gaullistas y, con mayor razón aún, a las organizaciones herederas de la derecha liberal o moderada, de las que la Unión para la Democracia Francesa (UDF) ${ }^{1}$ constituye una expresión histórica, se puede sin duda hablar de un ángulo muerto politológico. Una de las razones de este desinterés, según nosotros, se debe al hecho de que la tipología de Maurice Duverger ${ }^{2}$, por muy heurística que sea, condujo a los investigadores a focalizarse en las entidades partidistas que fuesen percibidas como más cercanas al modelo de los partidos Ilamados "de masas": los partidos comunista y socialista franceses. Esa ilusión óptica no sorprende en absoluto pues se sabe que Maurice Duverger se inspiró esencialmente en esas dos organizaciones partidistas para construir su tipología. Y aunque éste haya insistido en el deber de prudencia que exige el manejo de tales tipos ideales cuyo formalismo dificulta necesariamente la proyección hacia realidades empíricas, la comunidad científica tendió a confundir el modelo con la realidad, y viceversa. Sostenemos que una de las consecuencias de aquello fue apartar a las formaciones políticas conservadoras del campo de la investigación sociológica debido a una supuesta impureza empírica. Desde entonces, durante aproximadamente cuarenta años, los partidos de derecha padecieron de una suerte de ilegitimidad científica. Por ser aparentemente demasiado alejados de los partidos de masas y, en cierta medida, de los partidos de cuadros, tanto en su forma como en su ideología, fueron considerados como partidos por defecto, que no merecían una verdadera atención de parte de los especialistas de los mundos partidarios.

Por suerte, los tiempos, en lo que se refiere a la imaginación tipológica, han cambiado. El famoso díptico de Maurice Duverger, según consta en los trabajos de la mayoría de los teóricos actuales de los partidos políticos, aparece hoy en día obsoleto. Nadie, o casi nadie, se atreve a clasificar los partidos franceses y europeos recurriendo a este esquema. La evidencia de los hechos también desmintió el pronóstico de Maurice Duverger, que planteaba la institucionalización y la generalización de los partidos de masas como estado avanzado de la democracia representativa moderna. Seguramente, la muerte lenta del Partido Comunista francés (Pudal, 2002), "partido de masas" por excelencia, "modelo", en el sentido casi artístico de la palabra, que inspiró al creador del "modelo" formal, contribuyó a falsificar la doble noción de partido de masas/partido de cuadros. Pero la extinción progresiva de esta categorización no ha desembocado en una nueva era de conceptualizaciones mucho más alentadora. Para convencerse, basta comprobar la diligencia con la que se instaló el concepto de "partido cartel" de Richard Katz y Peter Mair (1995), reproduciendo en parte el mismo error de reificación en el cual había caído antaño la comunidad científica. Bajo

$1 \quad$ N.d.T.: La UDF fue un partido político francés de inspiración democratacristiana fundado en 1978, que tuvo como líder a François Bayrou. Después de las últimas elecciones presidenciales en mayo del 2007, un congreso extraordinario de la UDF votó la incorporación del partido al Movimiento Demócrata (MoDem). François Bayrou sigue siendo el líder de esta formación política.

2 Ésta establece una distinción entre los "partidos de masas" y los "partidos de cuadros". 
la pluma de aquellos recientes inventores cuyo mérito académico, entre otros, radica en haber permitido la circulación de un modelo a la vez fonéticamente sugerente (partido cartel; partidos en cartel) y analógicamente conforme con nuestro conocimiento inmediato de la realidad partidaria, se puede entonces deducir la desaparición de los partidos de masas. En la mente de estos autores, el antiguo modelo no sólo habría mostrado así sus límites metafóricos frente al surgimiento de nuevas entidades partidarias, sino que el partido de masas se habría desmoronado concretamente -suponiendo que hubiese existido- y habría sido reemplazado por otra realidad Ilamada "partido cartel". Desde nuestro punto de vista, ninguno de estos dos modelos tuvo existencia en otro lugar que en la mente de los científicos. Ahora bien, esto no significa que no hayan sido o que no sean modelos útiles, ni mucho menos. Parafraseando a Guy Michelat y Michel Simon (2004), para quienes la clase obrera de la que antaño se hablaba era en parte un artefacto, podríamos decir que por un lado el partido de masas ya no es lo que nunca fue verdaderamente, y por otro que el partido cartel corre el riesgo de nunca convertirse en lo que tampoco es en la realidad. Vemos aquí los límites de la práctica tipológica cuando lleva a confundir, para decirlo con las palabras de Karl Marx, las cosas de la lógica con la lógica de las cosas, en vez de sólo cumplir con ser una etapa intermedia, un marco de pensamiento como diría Max Weber, que permite acercarse lo más que se pueda a las características partidarias.

Esta confusión nominalista, aún presente en nuestro subcampo disciplinario, no sólo tiene, por suerte, efectos colaterales perjudiciales, particularmente en lo que atañe al interés científico por los partidos de derecha. Tanto la muerte proclamada del modelo del partido de masas/partido de cuadros como el advenimiento anunciado de la cartelización de los partidos políticos tuvieron el efecto a la vez oportuno e involuntario de poner en un mismo plano de análisis a los partidos de izquierda, que se habrían "desmasificado", y a los partidos de derecha, que se habrían "modernizado". Para convencerse, basta con hojear la literatura científica y periodística que siguió la creación de la Unión por un Movimiento Popular (UMP) en el $2002^{3}$ cuando, incluso en nuestra disciplina, conciertos de alabanzas saludaron la aparición en el escenario político de una derecha por fin "moderna", "librada de sus notables" y "democrática", una derecha que por fin había dejado de ser "la más tonta del mundo" y en la cual incluso el Partido Socialista podía urgentemente inspirarse (Fretel, 2005).

Asimismo, se estableció un cierto acuerdo en la comunidad científica para afirmar que la mayoría de las organizaciones políticas contemporáneas, tanto de derecha como de izquierda, desde la UMP hasta el Partido Comunista, son el blanco del proceso de "cartelización" cuyos efectos serían, en desorden, el electoralismo, el incremento de la colusión interpartidista y una cesura más grande que nunca con la sociedad civil ${ }^{4}$. A pesar de los riesgos inherentes a tal generalización, la analogía con la empresa que arrastra la noción de partido cartel rehabilitó

3 N.d.T.: La UMP es un partido político francés de derecha, Ilamado primero Unión para la Mayoría Presidencial, con vistas a sostener la candidatura del presidente Jacques Chirac a su propia sucesión en el 2002.

4 Para profundizar en la noción de partido cartel con una mirada crítica, véase Aucante y Dézé (2008). 
ipso facto a los partidos de derecha como terrenos legítimos de investigación. Se puede al mismo tiempo constatar que la historia paradigmática con fuerte propensión tipológica, que podemos rápidamente bosquejar desde Maurice Duverger hasta Richard Katz y Peter Mair, ha dejado huellas. Hoy en día, los estudios sobre los partidos de derecha son todavía los más escasos de todos, lo que comprueba que el reajuste aún no ocurrió, e incluso que numerosas suspicacias infrateóricas pesan irresistiblemente sobre esas formaciones. Éstas son todavía consideradas como avatares, como organizaciones con estructuras excesivamente laxas cuyos líderes actuarían con total independencia por falta de centralismo o de coerción de parte de su agrupación, pero también por falta de militantes. No obstante, observamos desde hace algunos años un leve aumento del número de estudios sobre la derecha, trátese de la derecha gaullista -neogaullista o postgaullista- o de la derecha moderada representada desde hace poco por el Movimiento Demócrata $(\mathrm{MoDem})^{5}$. Una revisión general de aquellos estudios recientes revela cuán provechoso resulta probar la operacionalidad de los modelos de análisis dedicados a los partidos políticos, confrontándolos con las características sociales, societales y organizacionales de las expresiones de la derecha francesa. Pues una vez abandonada la idea groseramente subjetiva según la cual la derecha -o las derechasserían colectivos tanto conservadores como desorganizados, resulta interesante estudiarlos no por lo que deberían ser en función de tal o cual tipología, sino por lo que son, vale decir, agrupaciones políticas con sus principios de institucionalización. Sólo de esta forma se vuelve posible generalizar, afinar, revisar o derrumbar los conceptos corrientemente empleados para comprender racionalmente el funcionamiento de las organizaciones políticas. Es lo que nos proponemos hacer aquí refiriéndonos a nuestro trabajo sobre la UDF, Ilevado a cabo desde el año 1998 hasta la fecha. En esta perspectiva, la UDF -o el MoDem- puede aparecer como un caso emblemático, en la medida en que la ciencia política, y con ella la mayoría de los manuales y obras teóricas sobre los partidos políticos, le denegó durante mucho tiempo el estatus de partido político stricto sensu. Por falta de suficiente "consistencia", "democracia interna" y "progresismo ideológico", dicha organización partidista fue calificada de "partido de notables", vale decir, de una "cáscara vacía", carente de militantes y, al mismo tiempo, provista de dirigentes "individualistas". En contraposición con aquellas prenociones, nuestro estudio intentó mostrar, por una parte, que se podía estudiar la UDF como un partido político como los demás, o sea como una institución partidaria, con sus reglas, sus roles, sus normas, en fin, con su conjunto de coacciones sociales sin las cuales no pueden realizarse los involucramientos individuales y colectivos que la hacen existir. Por otra parte, se postuló que la UDF también podía ser estudiada como un objeto capaz de hacer progresar la teoría general de los partidos políticos. En este artículo insistiremos

5 No pensamos que la desigualdad de tratamiento de la cual sufren los partidos de derecha tenga como única causa la ortodoxia con la cual algunos autores se reapropiaron el modelo de Maurice Duverger. Sin duda existen otros factores explicativos. Por ejemplo, habría mucho que decir y entender acerca de las elecciones personales de los objetos de investigación. Es muy probable que aquellas elecciones sean influenciadas, al menos en parte, por el ethos social y/o político de los investigadores. Esta perspectiva, eminentemente epistemológica pues alude a la relación íntima con el objeto, es una de las preguntas más difíciles de abordar hoy en día por ser una de las más polémicas. Estamos sin embargo lejos de pensar que aquellas elecciones sean sólo producto de prejuicios políticos. 
en particular en dos aspectos del funcionamiento de la UDF susceptibles de dar lugar a un debate en el campo de la formalización teórica sobre los partidos políticos. Mostraremos primero que la sociología que exige la objetivación de tal formación política puede ser un medio para enriquecer algunas reflexiones en cuanto a las maneras de ser de los dirigentes y a lo que es la militancia partidaria. Luego, recurriremos a nuestras observaciones empíricas para subrayar el aporte de un enfoque en términos de institución partidaria.

\section{EL FIN DE LOS NOTABLES}

Hasta hoy en día, uno de los reflejos más frecuentes en la sociología de los partidos consiste en asimilar a los dirigentes de derecha con notables. Esta manera de caracterizar al personal político electo de derecha e, indirectamente, de definir así lo que son los partidos de derecha, vale decir testaferros partidarios, puede recordar la extrema rudimentariedad de las expresiones valoradas por los etnometodólogos (Cicourel, 1979). Plantear que los dirigentes de derecha son notables en la mayoría de los casos equivale a recurrir a una especie de "et cetera", fingiendo aportar una respuesta a lo que exige al revés un cuestionamiento riguroso así como una exploración empírica. Notemos de paso que tanto los dirigentes del Partido Socialista como los del Partido Comunista no se salvan de este tipo de asimilación, con la diferencia de que la analogía es mucho más controlada. A propósito de la derecha, esta facilidad de lenguaje no tiene evidentemente el mismo sentido en la mente de todos los autores que escriben sobre ella. La práctica del oxímoron viene a veces a atenuar los supuestos heroizantes y anacrónicos que encierra la palabra "notable". Se habla por ejemplo de "notables modernos" o de "tecnotables" (Gaudin, 2007). Sin embargo, la ambigüedad con la cual es usado el vocablo requiere algunas precisiones.

Para empezar, nos parece precipitado hacer como si, desde siempre, la derecha moderada hubiese sido constituida por representantes de una misma categoría social sin que este término haya sido seriamente definido ni historicizado. En efecto, ¿qué se entiende con la palabra "notable"? Todo lleva a pensar que esta expresión, a pesar de pertenecer a una época en la que se delimitaba a un grupo social posterior al Antiguo Régimen ${ }^{6}$, sirvió para designar un personal político que, gracias a su fortuna personal así como a la estima social de la cual gozaba, se impuso en el campo político casi naturalmente. Su escasa propensión a descansar en una organización partidaria sería inversamente proporcional a los recursos adquiridos fuera del juego político. Sin embargo, el historiador Christophe Charle (1991) mostró que durante los siglos XVIII y XIX los notables no sólo se transformaron tanto socialmente como económicamente, sino que también se renovaron. Por ende, cabe preguntarse en qué medida los especialistas de la derecha, al esgrimir la figura del notable, no estarían manipulando en realidad una pseudonoción, la cual remite menos a una realidad que a un mito o una caricatura ${ }^{7}$. Es lo que nos invitan a pensar los trabajos de Eric Phélippeau sobre el barón de Mackau. Por lo demás, este autor ahonda en la crítica demostrando que quienes recibían el

\footnotetext{
Para profundizar en la noción de notables en Francia, véase Tudesq (1964).

Véase la contribución de Sorbets (1988).
} 
apodo de "notables" desde fines del siglo XIX ya se habían aclimatado a la política "moderna". Sobre este punto, la observación que realiza el autor tras estudiar las elecciones municipales de 1889 resulta esclarecedora:

\begin{abstract}
"Más que nunca, esta campaña revela la ósmosis creciente entre dos mundos cada vez menos antagonistas: el de los grandes notables y el de partidarios, después de que algunos grandes notables como Mackau hayan aceptado dar el salto y convertirse a la política sin abandonar del todo sus antiguas maneras de actuar; y luego de que otros, más modestos, hayan encontrado junto a la elite parlamentaria de la nobleza o de la alta burguesía los fondos o las protecciones necesarias para afirmar su ambición de representación" (Phélippeau, 2002: 304).
\end{abstract}

Si bien el uso del término de "notable" permite señalar y caracterizar algunas propiedades no partidistas pero que intervienen no obstante en las condiciones de elegibilidad de los candidatos a cargos de representación popular, es necesario subrayar que el notabilismo no es algo que se pueda sistemáticamente contraponer al "partidarismo", valgan las expresiones. Los estudios más contemporáneos sobre la derecha no-gaullista que, casi sin excepción, adoptan el vocablo, incitan a interrogar de nuevo lo que constituyó uno de los marcos interpretativos de aquella tendencia política hasta la fecha. El hecho de que los "notables" de derecha actúen impulsados en apariencia por el rechazo de una forma específica de alistamiento partidario no contradice el hecho de que se encuentren efectivamente, de una manera u otra, ceñidos dentro de colectivos o marcos apremiantes, o involucrados en situaciones de interdependencia y alianzas que les vuelven dependientes de las reglas de una organización. Una observación preliminar de aquellos dirigentes deja pensar, más allá de las palabras que les designan y de los términos que les caracterizan, que actúan con extrema independencia con respecto al partido y a los militantes. Esa es, por lo menos, la impresión que los políticos electos dejan de sí mismos y es también lo que ellos mismos dicen que son en el partido. Sin embargo, un estudio más completo, que recurra a la técnica biográfica y que requiera una etnografía multinivel ${ }^{8}$, permite no sólo mostrar el reduccionismo que conlleva el uso del término de notable, sino también que aquellos agentes electorales y partidarios están mucho más subordinados de lo que se suele creer a los marcos institucionales en los cuales se mueven.

Es verdad que los dirigentes centristas -expresión que alude exclusivamente al personal político de la UDF con cargos de elección popular, pues los que tienen un mandato electivo ocupan la mayor parte del organigrama del partido- parecen actuar como empresarios muy independientes que privilegian la defensa de sus intereses. No sólo parecen tener a su disposición todos los medios para cultivar su autonomía, sino que también disfrutan de cierta omnipotencia en su partido, la cual contrasta con el margen de maniobra y el poder efectivo

8

Con la noción de etnografía multinivel nos referimos al trabajo de observación que consiste en seguir a los encuestados a sus distintos lugares de ejercicio del oficio político. Se trató de seguir a los dirigentes con cargos de elección popular tanto en sus instituciones locales (administraciones locales y regionales, asociaciones diversas, etc.) como en el seno del partido al cual pertenecen (sección, federación departamental, sede nacional, tendencia más o menos formal). 
de sus mandantes dentro de la organización. Esta asimetría podría entonces entenderse como señal indiscutible de su hipernotabilismo. Pero sacaríamos probablemente conclusiones apresuradas si sólo nos quedáramos en lo aparente y concluyéramos que la UDF sólo es un partido de dirigentes que ocupan cargos de elección popular, y más aún un partido "de notables". Si bien la densidad militante en la UDF es muy reducida comparada con el Partido Socialista o incluso actualmente con el Partido Comunista, nos arriesgamos a pasar por alto una parte de la sustancia de la UDF al no prestar atención a la vez a los entornos partidistas en los cuales aquellas carreras se arraigan y a las características propias de esta institución partidaria, la cual es mucho más apremiante de lo que se suele creer. Primero, al contrario de lo que se puede leer en varios manuales, los dirigentes centristas no tienen un origen social más favorecido ni acomodado que el conjunto de los profesionales de la política. En este sentido, su elegibilidad no está respaldada por un patrimonio familiar o social más importante que el de sus competidores. Segundo, como hemos mostrado en nuestra tesis (Fretel, 2004), esos "independientes" han tenido una trayectoria militante compuesta de compromisos religiosos, cívicos, humanitarios o partidistas. Nada de la estima social de la cual suelen gozar existe fuera de sus carreras militantes concretas, las cuales les permitieron adquirir saberes en materia de acción colectiva pero también incorporarse a diversas redes sociopolíticas a las cuales muchos de ellos permanecen fieles. En otros términos, su presencia en el partido no significa en absoluto que no cuenten con apoyo tanto dentro como fuera de su organización política. Sin duda, logran con mucho brío mantener intacta la ley de hierro de la oligarquía, pero sin que eso signifique que hayan desdeñado a los grupos sociales más o menos movilizados que les siguen prestando su apoyo. Para mantenerse en las posiciones que ocupan tienen que efectuar un trabajo constante de activación de redes partidarias y no partidarias que contribuyen a la perpetuación de su liderazgo. Pero han de preocuparse también por mantener cierta porosidad entre todos esos mundos, y por alimentar la fe militante dentro, alrededor y fuera del partido en función de las causas defendidas, debido a las lógicas diferenciadas que determinan la razón de ser de cada uno de esos grupos. Tales como se presentan esas configuraciones partidistas en cada uno de los territorios donde la UDF existe en mayor o menor grado, el sustrato partidario, dentro y fuera de los límites stricto sensu de la organización, influye sobre los dirigentes electos por votación popular a través de una variedad de colectivos ante los cuales los dirigentes tienen que explicarse, estar a la altura de su rol de portavoz, e incluso justificar su calidad de representantes legítimos de esa diversidad de voluntades generales. En este sentido, éstos se vuelven estratégicamente independientes sólo si logran acumular suficientes recursos colectivos como para preservar su rol de delegación. Y, en el caso de los dirigentes centristas con cargos de elección popular, esos recursos colectivos tienen que ser cultivados no sólo en el partido con el fin de conservar el monopolio de la representación partidaria, sino también fuera de él para conservar la legitimidad de presentarse como el menos partidista de todos los competidores del juego político, como el más abierto o el más desinteresado de todos los hombres de aparato.

Así pues, al plantear de otra forma el problema de los resortes de la legitimidad y de la elegibilidad de los dirigentes de la derecha moderada -O del centro-, nos percatamos del reduccionismo de hablar de "notables" o de representantes electos independientes. Sobre aquellos agentes políticos, sólo podemos invitar a los politólogos a llevar a cabo encuestas 
sociológicas técnica y teóricamente comparables a las que existen sobre el Partido Socialista por ejemplo ${ }^{9}$. La sociología de los partidos políticos debe prestarles atención y objetivar el conjunto de los colectivos partidarios o parapartidarios que les rodean, sin los cuales aparecerían ilusoriamente como seres desprovistos de recursos y capital. Dicho esto, nuestro propósito no es volver hacia lo general y borrar todo lo que constituye la especificidad de este personal partidista. Pues una vez que se dijo todo lo que éste debía al conjunto de las instituciones sobre las cuales fundaron su liderazgo, queda pendiente desvelar el enigma que caracteriza las razones de su individualismo calificado por algunos de "congénito". Y, una vez más, sólo se puede resolver esa interrogante examinando la naturaleza de la institución partidista a la que pertenecen.

Todo, o casi todo, en las maneras de actuar de los dirigentes centristas recuerda su singular autonomía. La burocracia del partido con la que se relacionan es muy poco desarrollada. Por lo tanto, no es capaz de imponer reglas estándares a sus miembros, no "forma" a los cuadros del movimiento, no se encarga de la elaboración ni de la difusión de una ideología para encuadrar las actividades partidarias, y no interviene de ninguna manera en la construcción de las biografías militantes. La mayoría de las veces, las decisiones se toman a puerta cerrada y los militantes son expresamente invitados a validar los dictámenes tomados más arriba. Del mismo modo, en cada una de las federaciones la probabilidad de producirse un cuestionamiento del liderazgo existente es más que ínfima. En general, los adherentes plebiscitan a los elegidos que les representan, incluso cuando éstos fomentan una escisión de mayor o menor envergadura o cuando divergen ostensiblemente con respecto a la línea del partido. Entonces, para quienes observan con regularidad esta organización, el nivel de peligro, es decir, el clima de disenso así como las amenazas permanentes de exit levantadas por tal o cual dirigente, es particularmente elevado. En suma, la disciplina del partido es casi nula y los pequeños arreglos entre dirigentes con cargos de representación popular son casi la regla, en la mayoría de los casos. Teniendo en mente los estudios sobre el Partido Comunista de antaño, se puede afirmar sin rodeos que la UDF no es en absoluto un partido que ejerza un dominio sobre sus miembros. ¿Podemos sin embargo concluir que la realidad del partido sólo se circunscribe a los dirigentes electos? Aquí también hay que desprenderse de toda ilusión del conocimiento inmediato de la realidad partidaria. Pues este independentismo dirigente se debe tanto a las características sociales de los dirigentes centristas como a la estructura del partido que les convirtió en portavoces. Uno de los elementos organizacionales de la UDF permitirá ilustrar nuestro planteamiento.

Hemos visto anteriormente que el cursus honorum de los dirigentes centristas se caracterizaba en particular por una carrera iniciada con hazañas acontecidas al margen del juego político, para luego abrirse hacia compromisos y adhesiones partidarias. Sólo una parte reducida de los dirigentes fueron iniciados en las reglas de la organización política alistándose tempranamente en agrupaciones juveniles controladas de cerca o de lejos por los partidos emparentados con la UDF. Cualquiera sea la situación, todos aquellos ingresos

\footnotetext{
$9 \quad$ Véase Sawicki (1997).
} 
a la institución partidaria centrista fueron marcados por el sello de la improvisación. La aculturación partidaria se realizó por tanteos y sin un fuerte sostén burocrático. Desde este punto de vista, los más antiguos en el partido conocieron las mismas pruebas iniciáticas que los que se unieron a la organización centrista más adelante. De esta forma, todos ingresaron al partido descubriendo, contra toda previsión, un universo de reglas relativamente laxas, dentro de una organización sin reales recursos financieros ni materiales. Por consiguiente, el asumir el rol de responsable de la UDF, aunque sólo fuese a nivel local, implicó para aquellos dirigentes tener que enfrentar situaciones de penuria tanto humanas como logísticas y compensarlas importando sus propios recursos de emprendedores de causa. El ascenso en el partido para estos dirigentes tuvo lugar a pesar de condiciones administrativas y financieras altamente precarias, donde todo pareció arreglarse como si no hubiese "piloto en el avión". Este tipo de trayectoria, en ciertos aspectos comparable a la de los creadores de empresas abandonados a su suerte, tiene algo parecido a la autodidaxia. Aquellos dirigentes forjaron su vocación partidaria con la sensación de "no deberle nada al partido", o de siempre haber tenido que hacer todo "por su propia cuenta", y abrigan a la vez hacia su partido un resentimiento por la poca atención recibida. Debido a la extrema oligarquía que impera a nivel federal desde que existe la UDF, las sucesiones de dirigentes en las que la transmisión de poderes no ocurriera de manera brusca fueron escasas, generando incluso enemistades. En esas condiciones, que reflejan la predominancia de los dirigentes con cargos de representación popular en el partido, cada uno de los nuevos dignatarios locales del partido tuvo que ascender en la agrupación ocupando un segmento de la institución que fue aparente o efectivamente dejado en barbecho por su antecesor. Sólo algunos militantes atentos y resistentes pudieron convertirse en testigos del cambio y garantizar así un mínimo de memoria partidaria a nivel del distrito ${ }^{10}$. En el caso del personal político de la UDF, esta iniciación de institución marcada por la consigna "hazlo tú mismo" opera como un rito de ingreso al partido, absolutamente decisivo. Se trata del acto a través del cual los futuros dirigentes se relacionan con su partido bajo una modalidad autodidacta. Paradojalmente, ingresar a la UDF en calidad de "notable" exige hacerse cargo de una amplia gama de tareas que incumben habitualmente a los adherentes de base. El hecho de que los primeros pasos en la organización de aquellos dirigentes hayan estado marcados por cierta penuria no significa sin embargo que "el partido" no tenga ninguna influencia en su promoción a cargos electivos. En efecto, numerosos saberes, trucos del oficio político, algún reconocimiento, la marca UDF y los listados de militantes fueron entregados a los nuevos responsables de federaciones. Dicho esto, el apoyo logístico y militante se caracteriza por su escasez, lo que contribuye probablemente a explicar que las víctimas directas de esa débil redistribución sólo conserven en mente el recuerdo de todo lo que les hizo falta. Según cuentan, los primeros pasos en el partido se caracterizan a la vez por un período en el que el dirigente tuvo que levantar una sección partidista abandonada, invitar a algunos de sus compañeros de vida asociativa a sumarse a su proyecto, y comportarse por un tiempo como un humilde agente de servicio a cargo de "tareas inferiores". No es entonces de extrañar oírles explicar que llegar

10 Sobre las alternancias en las federaciones de la UDF, véase Fretel (2004). 
a ser miembro de la UDF constituye "un verdadero sacerdocio". Para retomar las palabras de Daniel Gaxie (1977), en la UDF no existe ningún efecto "sobrerregenerador", vale decir, ningún "combustible" susceptible de generar un exceso de energía puesta al servicio del partido. Cada adhesión, tanto de parte de los dirigentes con cargos de elección popular como de los cuadros intermedios, es vivida al contrario como una entrega que ignora el juego del toma y daca. Esta manera de comportarse en la institución que conduce a ver al partido como algo tanto maleable como frágil, e incluso inseguro, predispone a los dirigentes con cargos de representación popular a forjarse para sí mismos y sobre sí mismos un mito, el del líder heroico. Porque tuvieron que suplir las carencias de la organización, se perciben no sólo como supervivientes sino también como los nuevos dueños de la formación centrista. Su notoriedad precedió su ingreso al partido y fue confirmada a lo largo de su ascenso en la UDF gracias a su empeño para comportarse como hombres emprendedores que asumen solos todos los riesgos.

Estamos aquí ante una figura de dirigente electo por sufragio popular y de responsable de partido totalmente invertida respecto de lo que se puede observar en los partidos llamados "de masas" en los que los militantes llegan a ocupar, luego de varios ritos de consagración y varios tiempos de formación, cargos dirigenciales. De esta situación resultan dos sentimientos que podrían parecer contradictorios pero que explican por qué aquellos dirigentes viven como un verdadero insulto el calificativo de "notables". Por un lado, conservan en mente el hecho de haberse impuesto a pesar de la inercia propia del partido, por otro, están convencidos de haber ingresado al partido de manera totalmente desinteresada, debido a que la organización parece a priori ofrecer demasiado poco a quienes se integran a ella. Este último punto les lleva a pensar que no tienen nada en común con los profesionales de la política, vale decir aquellos que persiguen únicamente una retribución inmediata.

Tenemos aquí una llave importante para comprender el partido centrista en la medida en que estos dos factores -las disposiciones anteriormente adquiridas y las experiencias partidarias acumuladas en la interacción con cierto tipo de institución- permiten entender a la vez lo que produce unidad -el ethos centrista-y lo que provoca eventualmente alguna disparidad -el descubrimiento trabajoso y "solitario" de la institución, lo cual predispone a mantenerse a distancia del juego partidario-. Es este rasgo común a todos el que puede, al menos en parte, explicar las diferencias, e incluso las disidencias, en el partido. Aquella relación peculiar con la institución contribuye también a explicar que la UDF sea percibida como un partido de dirigentes omnipotentes. Esperamos haber demostrado que este planteamiento no es contradictorio, ni mucho menos, con el hecho de subrayar al mismo tiempo todo lo que esos comportamientos "anti-institucionales" deben a la institución en la cual se originan, vale decir, a la fuerza de lo objetivado que es el partido ${ }^{11}$.

11 Las recomendaciones de Jacques Lagroye (2002) nos fueron más que útiles para intentar "escapar al doble riesgo del sociologismo mecanicista que postula el efecto inmediatamente operatorio de 'determinismos extrínsecos e instantáneos', así como del subjetivismo (o de un intersubjetivismo) espontaneísta que sólo quiere ver la libertad reflexiva del actor en la producción de sus actos". 
En suma, las tipologías, cualesquiera que sean, no tienen que desviar nuestra atención de lo que la agrupación produce sobre sus miembros, y eso a pesar de que dicha agrupación se presente como una asociación particularmente laxa en apariencia. Y en el caso de que el sociólogo tuviera que clasificar los hechos partidarios en la óptica de un trabajo comparativo, nos parecería imprescindible no perder de vista la preocupación por establecer paralelos entre distintos tipos de institucionalización partidaria, entre órdenes institucionales más o menos similares, entre formas de rutinas y de involucramientos más o menos regulados dentro de y por la institución, en vez de identificar propiedades genéricas abstractas en las cuales el partido, los dirigentes y los militantes se encontrarían relacionadamente disociados. Al no haber podido -O sabido- "ubicar" tan fácilmente en uno u otro modelo estándar la formación política a la que pretendíamos estudiar, tuvimos que apartarnos de los modos de pensamiento en los cuales "las copias hacen pleonasmo con la realidad" (Bourdieu et al., 2005: 75).

\section{II. ¿EXISTEN LOS MILITANTES DE DERECHA?}

Describir a grandes rasgos a los dirigentes de derecha o de centro con cargos de elección popular como a "notables" no es el único daño colateral causado por la sociología de los partidos políticos. De nuevo, nos parece que la tipología de Maurice Duverger así como sus usos ulteriores acreditaron la idea de que la militancia era sólo una característica de las formaciones de izquierda. Y el examen de los trabajos sobre el compromiso partidario no deja subsistir ninguna duda en cuanto a esta apreciación. El extraordinario desequilibrio entre los materiales de investigación disponibles sobre la militancia de izquierda y de derecha proporciona un índice indiscutible al supuesto según el cual la derecha -o las derechasno contaría con el capital partidario que son los adherentes de base, más o menos activos. Porque se dijo que aquellas formaciones conservadoras descansaban únicamente en un personal político con cargos de representación popular y que reunían esencialmente a las fracciones más burguesas de la población francesa -otro punto implícito que conlleva el término de "partido de notables"-, las derechas francesas serían propensas, y eso de manera casi congénita si damos crédito a algunos autores, a tomar partido sin partidarios. Ahora bien, aquí no podemos sino constatar el carácter precipitado de aquellas reflexiones. Las derechas, sean gaullistas o moderadas, pertenezcan al pasado ${ }^{12} \mathrm{o}$ a nuestro presente, tuvieron y siguen teniendo militantes. Poco importa en realidad con cuál noción se quiera identificar a quienes asumen el papel de sostenes más o menos activos para la defensa de las causas y estrategias propias del partido, y eso con mayor razón considerando que las palabras empleadas corrientemente por los politólogos no se ajustan siempre a los adherentes de derecha. Numerosas entrevistas nos han mostrado que estos últimos abogaban a menudo por la defensa de otro vocablo para nombrarles y también por la defensa de otra percepción de lo que hacen para movilizarse. Es posible que la focalización sobre el partido stricto sensu, que fue inducida por la noción de partido de masas, no sólo haya llevado a los especialistas

12 Al parecer, varios historiadores contemporáneos no demostraron la misma ceguera, véase Jean-François Sirinelli (2006). 
a creer que los partidos de derecha no presentaban suficiente densidad física y moral como para que uno indagase su vida militante intrínseca, sino también que haya desviado la atención del observador sobre lo que está en juego en la órbita de las movilizaciones que circunscriben el partido.

Nuestro trabajo sobre los militantes de la UDF nos llevó a evitar todo tipo de absolutismo en lo que se refiere a la elección de las palabras que permitieron describir los compromisos centristas. Nos llevó también a ampliar lo más que se pueda el foco para tomar toda la medida de lo que significa ser "centrista" cuando uno pretende consagrarse al partido, dentro y fuera de éste. Nos pareció tanto más importante captar esta multiposicionalidad cuanto que nada se puede entender de la UDF sin hacer el esfuerzo de seguir a los adherentes a lo largo de su carrera militante, de manera diacrónica. Por lo tanto, cabe abarcar el espectro de sus adhesiones partidarias y no partidarias en su conjunto, las idas y vueltas que aquellos activistas realizan, vaivenes indisociables unos de otros para entender lo que motiva sus razones de actuar.

Tal como hemos demostrado en diferentes ocasiones, los adherentes centristas se caracterizan, según nosotros (lo que no significa que no tengan nada comparable con otros militantes de otras organizaciones políticas), por tener caminos de adhesión más que inciertos, a menudo $\operatorname{sinuosos}^{13}$, y en todo caso sujetos a numerosas preguntas existenciales (Fretel, 2004). Por eso, nos pareció útil a la comprensión de lo que son social y políticamente precisar que pocos entre ellos son quienes no hicieron nada más en materia de militancia que adherir a la UDF. En otros términos, en esta organización la adhesión plural es algo común, e incluso es coconstitutiva del ethos militante. La dimensión heurística de nuestros resultados, en la perspectiva de una reflexión sobre la militancia en los partidos políticos, descansa así en varias dimensiones de sus maneras de actuar que pretendemos ahora discutir.

Porque los adherentes centristas tienen en común el haber sido o/y ser más o menos expuestos al encuadramiento de la institución católica, es necesario volver sobre las tensiones contradictorias que experimentan antes y durante su adhesión al partido. A ese respecto, la cultura anti-partido adquirida durante la socialización religiosa contrarresta mucho, o por lo menos hipoteca, el deseo o la necesidad de comprometerse políticamente. Este elemento nos parece esencial para apreciar primero el estado de las motivaciones que provocan la adhesión al partido. Hablamos de fenómeno "paradójico" para expresar dos dimensiones indisolubles de su compromiso: la primera que conlleva la necesidad de comprometerse y realizarse en la actividad partidaria, remite a la voluntad de ir lo más lejos posible en materia de transformación del mundo, aunque esta exigencia implique abrazar una causa partidaria; la segunda se debe a la desconfianza, e incluso al rechazo hacia las luchas políticas y sobre todo partidarias, acusadas de aumentar la división, el fanatismo y la arbitrariedad entre los hombres. Para decirlo de otra forma, los adherentes de la UDF, debido a su ethos católico, son

13 Según el Evangelio, en el cual muchos militantes de la UDF se inspiran, "Dios escribe recto con líneas torcidas", lo que conviene bastante bien para dar cuenta de esas trayectorias. 
arrojados casi a pesar suyo entremedio del dilema sin solución que les plantea la militancia partidaria. Notemos, y esto tiene su importancia para la comprensión de los resortes de su compromiso, que esta ambivalencia es a la vez freno y motor de su deseo de tomar partido. Uno de los efectos, o una de las manifestaciones, es que viven tanto más lo que los lleva a militar que manifiestan una especie de distanciamiento hacia su organización política. El subrayar este aspecto permite abrir nuevas pistas para apreciar las razones del compromiso. En primer lugar, invita a interrogarse sobre cierto número de secuencias durante las cuales pudieron superarse ciertas formas de inhibición. Las razones del compromiso partidista de los militantes centristas atañen tanto a su socialización religiosa como a su interés por una organización relativamente laxa en cuanto a su organización. Esto permite también evitar las lecturas demasiado anacrónicas de los flujos de la adhesión al interpretarlos como trayectorias lineales en las cuales sólo cuenta la voluntad de formar parte del juego partidario. Nos parece esencial aquí considerar la adhesión como una decisión "límite", tomada, como se dice trivialmente, sobre el filo de la navaja. Por cierto, como escribe Pierre Favre, "el mundo pasado y presente, en lo que ha acontecido, es integralmente determinado e integralmente conocible por la ciencia" (Favre, 2005: 63-64). Por lo tanto, porque ese pasado no ha sido recorrido fatalmente, porque ha sido balizado por sucesiones de imprevistos ${ }^{14}$, porque resurge en cierto modo cuando reaparecen las interrogantes lancinantes acerca de la compatibilidad entre un ideal humanista y/o religioso y lo que es considerado como politiquería, este pasado no es del todo pasado, y los dilemas que lo balizaron anteriormente vuelven a la superficie sin fin ni remedio. Esta característica lleva a los adherentes a cultivar esta forma de distanciamiento de la cual ya hablamos, pero también a elaborar un compromiso intermitente en el que la alternancia entre exit, voice y loyalty es asumida y presentada como un arte de existencia. "Largarse" gustan decir los que se despiden del partido, no tanto por disgusto, ni tampoco por desencanto, sino porque para ellos ha venido la hora de hacer política por otros medios, de irse para volver mejor en cierto modo. Estas son modalidades frecuentes de la adhesión. Este aspecto, que fue a veces interpretado como señal de un compromiso de menor intensidad y explicado por el carácter burgués de la militancia de la UDF, es en verdad común. Claro está, hablar de burguesía a propósito de la membresía del partido puede por cierto ayudar a situar el nivel social, cultural y económico de los individuos dentro de un muy esquemático espacio social de las posiciones. Sin embargo, esta observación tiene una utilidad casi nula en lo que respecta a la caracterización de un estilo militante. En este sentido, podemos decir que todo, o casi todo, queda por ser investigado en materia de sociología de la militancia partidaria en los medios acomodados.

Por fin, precisemos que este hábitus específico observable entre aquellos adherentes se ajusta bastante bien a la forma del partido. Como ya explicamos, la UDF, debido a su historia pero también al hecho de que sus representantes electos no dejan de privatizar el capital partidario que han ido constituyendo para fines personales, presenta una estructura partidaria atrofiada en lo que se refiere a su burocracia. Esto delata una dejadez organizacional

14 Rescatamos aquí lo que Jacques Lagroye entiende por "imprevisto", a saber, lo que es "irreductible a una concatenación ineluctable". 
cuyos efectos son relativamente "hobbesianos", para retomar la fórmula de Rémi Lefebvre y Frédéric Sawicki (2006), y en el cual el fetichismo de la delegación es intenso. Por lo tanto, y tan paradójico como pueda parecer, este diseño institucional conviene tanto más al conjunto de los adherentes cuanto que se opone en todo punto a las organizaciones en las cuales el enrolamiento o, por decirlo de manera eufemística, la disciplina de partido, sería la regla. A riesgo de poner en peligro la democracia interna, la elasticidad de las reglas del juego partidario, en el caso centrista, constituye la garantía de que el ethos centro-católico no puede disolverse totalmente en los juegos del partido, de que no puede ser aniquilado por una burocracia tentacular.

Tratándose de no sucumbir a la tentación de asimilar a la UDF con una "cáscara vacía", idea planteada en repetidas ocasiones por no haber sabido descentrar la mirada de la atonía aparente de la vida de este partido, resulta provechoso prestar atención a la ecología militante en la cual se desenvuelven esas movilizaciones partidarias. En efecto, analizar las trayectorias militantes como otras tantas trayectorias atravesadas simultánea o alternativamente por otras historias militantes anexas y conexas pasadas y/o presentes en tal asociación parroquial o tal estructura sociocultural, caritativa o humanitaria, es mostrarse atento al espacio entero de los compromisos posibles, sean éstos partidarios o no partidarios. Obligarse a tomar en cuenta fenómenos de compromisos plurales que involucran a los militantes del partido conduce a ampliar el foco al conjunto de las redes sociales que encierra la pertenencia al partido de esos agentes sociales. Esto conlleva lógicamente repensar el perímetro del compromiso partidario e incluir en él, sin exclusiones, tanto las adhesiones partidarias como no partidarias que constriñen a los adherentes. En cuanto haya que dar cuenta de esas existencias plurales e indivisibles, se debe también emprender un trabajo de redefinición de los conceptos de militancia y de adhesión para preguntarse lo que el recurrir a aquellos conceptos permite o no aprehender. Por consiguiente, debemos ser prudentes ante el implícito que convierte en una vara de medir a la adhesión que podríamos llamar "adhesiva", entendiéndose la más "cronófaga", la más oblativa, en síntesis la más fundamentalmente militante. Bien se ve aquí cómo después de haber tomado conceptualmente la conducta del militante comunista como referencia en la sociología de la militancia partidista, se trasladó esta esquematización sobre otras manifestaciones del compromiso, haciendo de éstas versiones deterioradas del compromiso. Dicho de otra manera, si los partidarios de derecha no resistieron la comparación con el Partido Comunista, no fue por haber fabricado una militancia de menor calidad, sino porque "inventaron" otra cosa que aquello en contra de lo que aprendieron a luchar en el seno de su organización. A contracorriente de esos supuestos, aquí las defecciones más o menos duraderas, las reincorporaciones después de dos o tres años de ausencia, las afiliaciones sin pagar cotizaciones, el estar en el partido sin estar completamente involucrado en él para algunos miembros, el pagar su cuota sin estar físicamente en el partido, deben ser estudiadas como modalidades eventuales de un involucramiento más o menos importante en las actividades del partido, aunque concretamente nada en esta materia parezca tan sencillo (Lefebvre, 2006). Pero estas modalidades deben también ser aprehendidas como otros tantos actos posiblemente entrelazados con formas de compromisos distintas de las partidarias, susceptibles de fortalecer, suspender, descentrar o relativizar la apetencia 
partidaria. Estudiar las prácticas militantes requiere asimismo entrar en el universo mosaico de la economía general del compromiso de los individuos, e incluso en la economía a secas de la existencia individual y colectiva de los agentes sociales.

Así, al tomar en cuenta las características de esas militancias de derecha o de centroderecha, se vuelve aún más necesario recurrir a una definición, la más amplia posible, de las organizaciones políticas. No con el objeto de diluirlas en un conjunto más vasto de actividades sociopolíticas, a riesgo de apartarnos de la empresa de comprensión de los partidos políticos como tales, sino más bien para inscribirlas en medio de las configuraciones en las cuales se forman y en las cuales los adherentes las modelan a su manera. Sólo bajo esta condición se puede evaluar el arraigo de las organizaciones partidistas, de las redes que las irrigan, directa o indirectamente, pero también de los modos de gobierno que las caracterizan, de los involucramientos -militantes, en este caso- que les dan su forma concreta. La sociología de la militancia no puede escapar a este marco de análisis, a menos que esté reducida a la auscultación de la vida de los partidos, sin otro punto de vista, sin otro punto de apoyo que permita pensar las organizaciones como otros tantos espacios de movilizaciones, ejercidas tanto al interior como al exterior de sus fronteras.

\section{LA RETRIBUCIÓN DE LAS CARRERAS MILITANTES}

Estas pocas precisiones que apuntan a dar cuenta, de la manera más general posible, de la realidad de la militancia centrista y a dibujar un telón de fondo que permita mostrar lo que puede ser la militancia partidaria, nos llevan a formular algunos comentarios acerca de los usos rutinarios de las teorías -o conceptos- sobre la militancia. Recordar esta dimensión lógicamente compleja de la militancia permite ante todo prevenirse contra las teorías "preconcebidas" que enuncian que amplios e inexorables procesos de individualización afectarían a la militancia contemporánea, al igual que al conjunto de las actividades sociales, entre las cuales no se salvarían ni la familia, ni el trabajo, ni la religión. La señal tangible de la progresión sin límite de la individualización aplicada a los partidos políticos sería la depreciación del compromiso colectivo y la tendencia al fin de la adhesión sin concesiones ${ }^{15}$. A riesgo de echar un vistazo demasiado rápido a esas tesis atribuyendo a sus autores lo que no precisamente enunciaron, plantearemos sin embargo que en la medida en que queda por demostrar con más argumentos y esfuerzo de historicización que la reflexividad de los individuos, el desplazamiento en las relaciones sociales entre el yo y el nosotros, son tanto recientes como crecientes (Corcuff et al., 2005), falta mucho para sacar a la luz la concatenación causal de la que la militancia más distanciada sería el efecto y el individualismo la causa ${ }^{16}$. En el caso de la derecha, tenemos la convicción de que este rodeo por las vías a veces sinuosas y ambivalentes de la adhesión pone en suspenso, hasta

15 Para hacerse una idea de los argumentos de los partidarios de este planteamiento crisológico, véanse Perrineau (1994) e lon (1997, 2005).

16 Se puede consultar el libro de Brodiez (2006), parcialmente escéptico sobre el carácter reciente de esos fenómenos de distanciamiento de los militantes con respecto a sus organizaciones. 
nuevo aviso, una serie de explicaciones hasta el momento nunca demostradas, las cuales retratan a los militantes de derecha $-y$ burgueses por añadidura ${ }^{17}$ - como poco propensos al compromiso ${ }^{18}$, muy distantes de las luchas partidarias y parcos en tiempo para convertir su pertenencia institucional en un esfuerzo continuo.

Hemos intentado sacar partido de todos los aportes novedosos de los enfoques contemporáneos sobre el compromiso. Es por ejemplo obvio que los trabajos que recurren a la noción de carrera fueron para nosotros fuentes de inspiración. El mérito de esta "nueva ola" epistémica es que incita a instalarse en perspectivas de investigación que hacen de la adhesión a tal o cual organización un hecho social total, que no puede circunscribirse a la sola exploración de las arenas partidarias. Sin volver en detalle sobre el programa de investigación que conlleva el uso de tal noción, conviene subrayar que se trata de tomar en cuenta a la vez la historia social de los individuos, las historias colectivas en las cuales están inmersos así como los efectos cumulativos y entremezclados de esas historias sobre su destino. La idea subyacente, si seguimos a los promotores de esas opciones teóricas y metodológicas, consiste en evitar el estudio unidimensional de la adhesión. Si realizamos un breve inventario de los estudios inspirados en este marco de análisis, nos percatamos de que los partidos políticos son relativamente dejados de lado, a nivel empírico, en beneficio de actores asociativos tales como los que circunscriben el campo del altermundialismo, entre otros. En lo que se refiere a nuestro trabajo, hemos intentado decir que este enfoque se imponía debido a las características sociales y morfológicas de la UDF.

Primero, estos enfoques recientes, lejos de agotar todos los beneficios posibles que se pueden esperar de ellos ${ }^{19}$, pueden ser considerados como vías alternativas a la sociología de las retribuciones de la militancia (Gaxie, 1977, 2005). Es verdad que una lectura demasiado expedita de la interpretación olsoniana que Daniel Gaxie realizó de la militancia política nos devolvería implícitamente a un tipologismo que no dice su nombre, en particular porque ese modelo se inspiró principalmente en el funcionamiento del Partido Comunista francés, juna vez más!, partido en el cual el exceso de representación de la clase obrera y la sociabilidad partidaria parecen formar un todo. Tomado al pie de la letra, fija las nociones que permiten describir el compromiso partidario, lo cual plantea dos problemas importantes, a nuestro juicio. Por una parte, se inspira en un punto de vista parcialmente miserabilista. En efecto, todo ocurre como si los militantes, aquí de origen popular aunque sean ignorados como tales y elevados tácitamente al rango de agentes universales, tuvieran todo por ganar sin nada que perder con su compromiso. Se postula además implícitamente una ignorancia

17 Otro lugar común de los estudios sobre la derecha: los militantes, en su mayoría, no sólo serían burgueses, sino que aquellos burgueses -y con eso nótese que no se dice nada de su hábitus militante- serían la mayor parte del tiempo reacios al compromiso político y social. Para convencerse de lo contrario, se puede consultar el conjunto de los trabajos de Michel Pinçon y Monique Pinçon-Charlot, véase en particular Pinçon y PinçonCharlot (2007).

18 Véanse entre otros a Bréchon (1999) e Ysmal (1989).

19 Pensamos que la ciencia política no sacó suficiente partido de la noción de carrera, a diferencia de la sociología. Véase al respecto el estudio de Darmon (2003). 
respecto del interés "interesado", por así decirlo, que puedan tener en militar. De hecho, no es casual si en el marco de este enfoque las retribuciones tienen como contrapartida la entrega de sí mismo de los militantes hacia la institución. Esta última expresión es tan hermosa metafóricamente como es también un obstáculo para entender cómo, en una relación a la vez de conocimiento y de desconocimiento de las relaciones de autoridad o de dominación, uno se compromete, se entrega en cuerpo y alma, con tanta ingenuidad, como lucidez y perplejidad. Por otra parte, nos parece que este análisis que tiene como prisma el juego de las retribuciones atañe más -para retomar la oposición de Canguilhem-a la mecánica que a la cibernética, en el sentido en que disocia con demasiada nitidez al que recibió alguna retribución de su partido, en lugar de procurar reunirlos analíticamente y pensarlos de manera dialéctica. Si nos hubiésemos inscrito en esta perspectiva reificante en la cual el adherente y su organización se mirarían con recelo, hubiésemos dejado escapar dos dimensiones fundamentales de la militancia centrista. Primero no hubiéramos podido aprehender lo que atañe a la virtuosidad ascética en la manera de comprometerse en el partido, donde la ausencia de retribución forma parte de lo que busca buena parte de los adherentes ${ }^{20}$. Este interés por el desinterés no esconde sólo la justificación de prácticas difícilmente confesables. Entregarse al partido sin esperar nada a cambio, aún más, esperar que lo entregado no llame a ninguna cosa a cambio, esperar desde luego que nada venga a manchar la belleza del gesto voluntario $^{21}$, constituyen dimensiones social e históricamente determinadas que la UDF, al igual que otros movimientos, despierta y recompensa sin recompensa. La entrega no agota por supuesto todas las dimensiones de la militancia centrista. Pero ésta es en parte irreducible a la búsqueda de gratificación. La fuerza motriz de la dimensión moral del compromiso tiene que ser si no pensada, al menos interrogada sociológicamente, de la misma manera que la felicidad de dedicar su tiempo y su energía puede ser considerada, después de todo, como algo primordial ${ }^{22}$. Asimismo conviene agregar que las retribuciones existen sólo a la altura de lo que los miembros de la organización quieren y pueden darle indirectamente. Todos los partidos políticos no tienen tanto que ofrecer. Existen casos en los que la condición del involucramiento militante descansa en el hecho de que la agrupación no dispone de suficientes recursos, medios de coerción y capital burocrático. Cada uno de los militantes teme que "demasiada estructura" les coaccione, y les prive de libertad ${ }^{23}$. ¿Acaso es necesario recordar que los militantes no siempre buscan lo que tiene precio? (Zunigo, 2003), aunque

20 El hecho de subrayar la importancia de la devotio entre los militantes no significa que no haya nunca actos provocados o recompensados por tal o cual incitación selectiva. Sólo queremos advertir contra un cuestionamiento sociológico que tendría como único objetivo el de develar lo que remunera material o simbólicamente el compromiso de los individuos. Nuestro propósito aquí sólo consiste en decir que en las organizaciones existen también actos realizados sin ningún provecho, que existen subespacios que tienen "leyes fundamentales distintas, irreductibles, las cuales albergan formas particulares de interés" (Bourdieu, 1994: 164).

21 No estamos lejos del mito del "buen samaritano" que Boltanski (1993) considera como la parábola del don absoluto.

22 A propósito de lo que conviene llamar la felicidad en la institución, véase a Lagroye y Siméant (2003).

23 Esta característica no sólo caracteriza a la UDF, sino también a otras organizaciones no políticas tales como ATTAC. Véase Cruzel (2004). 
se pueda hipotetizar que esa manera de entregarse al partido "sin escatimar esfuerzo" es aún más fácil de realizar cuando los que quieren dar de sí mismos viven desahogadamente.

Subrayar los límites que presenta la sociología de la militancia vista bajo el ángulo de las retribuciones que operan en ella no significa que haya que pasarla por alto. Además de permitir prestar atención a las gratificaciones, al afán de lucro o a la búsqueda de honores, esta problemática obliga al investigador a interrogar el funcionamiento de las instituciones partidarias -a reubicarse al centro de los mecanismos institucionales-, a develar su modo de gobierno y a identificar los procesos que (re)tienen a los agentes sociales en un contexto dado; lo que las perspectivas en términos de carreras militantes tienden a aminorar. Estas últimas, al seguir la trayectoria más o menos continua de los militantes, al identificar las etapas importantes que desembocaron en el compromiso militante así como las nuevas coacciones u oportunidades venideras que cada nueva etapa habría provocado, al convertir por último aquellas vidas adherentes plurales en la unidad de tiempo y de lugar a partir de la cual se descifra la militancia, tienden a no percatarse con suficiente acuidad de lo que las instituciones encierran de fundamental. Ni qué decir tiene que no sólo defendemos el uso alternado de las nociones de "retribución" y de "carrera", sino también y sobre todo que abogamos por una sociología de los partidos políticos inscrita en la problemática más amplia de la institucionalización del hecho partidario, o sea en el marco de una sociología que explora a la vez lo que tiene que ver con las reglas, los roles y las rutinas que conforman el partido, que son el partido -la institución en cierto modo-, pero también lo que resalta de los múltiples involucramientos, esperanzas, improvisaciones, subversiones e inventos cuya realización permite la institución, en síntesis lo que hace el partidario, el que toma partido, el que hace suya la institución para militar, tanto como ésta lo hace suyo.

Asimismo, lejos de afirmar que la sociología de los partidos de derecha es un ámbito más fecundo que otros en lo que se refiere a la comprensión de la militancia, nos parece que tiene el mérito de romper con las rutinas científicas así como con la afinidad conceptual que existió durante mucho tiempo entre el estudio de los partidos políticos y las organizaciones de izquierda. En este artículo sólo quisimos mostrar que las clasificaciones más o menos sofisticadas no deben en ningún caso desembocar en buscar dar la "buena definición" de lo que es un partido. Cada vez que uno se satisface con la aparición de una nueva tipología, tiene que recordar todo lo que ésta excluye de su campo de análisis ipso facto. Como Max Weber nos invita a hacerlo, hay que ser tan entusiasta en utilizarla como paso hacia el límite de la realidad que se pretende aprehender, como en preocuparse por sus inevitables límites. Tendríamos ganas de decir entonces que una buena tipología es una tipología que "no funciona", que no se ajusta del todo a la realidad, pero cuya incompletud es fuente de conocimiento. A pesar de todo pensamos que el horizonte analítico se debe encontrar en un conjunto de preguntas que permitan entender al final cómo cada agrupación partidaria adquiere poco a poco su forma institucional y cómo sus actividades y sus actores se ordenan en ella; sea o no imponente el "armazón" -para retomar las palabras de Maurice Duverger-que caracteriza a aquellas organizaciones. En efecto, hacemos la apuesta de que siempre existe más institución -o institucionalización- de la que se suele creer o captar cuando se mira la realidad partidaria. A eso le llamaba Durkheim "un orden de los hechos que presentan rasgos 
muy especiales: consisten en maneras de actuar, de pensar, de sentir, ajenos al individuo, y que son dotados de un poder de coerción en virtud del cual se imponen a él" (1983: 5-6). Los partidos de ayer, y más especialmente los partidos Ilamados "de masas", han sido presentados como organizaciones apremiantes que presentan cierta "rigidez" arquitectónica, mientras los de hoy, que algunos Ilaman "partidos cartel", al contrario, son descritos como instituciones más "fluidas" que nunca. Si antaño se cometieron excesos de lenguaje y de caracterización, ahora la tendencia apunta más bien a abrazar demasiado una visión asociológica a la que cuesta ver los hechos sociales como cosas, mientras que el examen de la realidad muestra que son mucho más regulados y previsibles de lo que se podría intuir. Ésta es en todo caso la lección que se puede sacar de un estudio sobre la derecha no-gaullista que presentaba al principio todas las apariencias de una "cáscara vacía".

\section{BIBLIOGRAFÍA}

Aucante, Yohann y Alexandre Dézé (dir.) (2008): Les transformations des systèmes de partis dans les démocraties occidentales. La théorie du parti-cartel en question, Presses de Sciences Po, París.

Bréchon, Pierre (1999): Les partis politiques, Montchrestien, París.

Boltanski, Luc (1993): La souffrance à distance, Métailié, París.

Bourdieu, Pierre, Jean-Claude Chamboredon y Jean-Claude Passeron (2005): Le métier de sociologue, Mouton de Gruyter, Berlín.

Bourdieu, Pierre (1994): “Un acte désintéressé est-il possible?", en Pierre Bourdieu: Raisons pratiques, Seuil, París, pp. 149-167.

Brodiez, Axelle (2006): Le Secours populaire français, Presses de Sciences Po, París.

Cicourel, Aron (1979): La sociologie cognitive, PUF, París.

Charle, Christophe (1991): Histoire sociale de la France du 19ème siècle, Seuil (Points), París.

Corcuff, Philippe, Jacques Ion y François De Singly (2005): Politiques de l'individualisme, La Discorde, col. Textuel, París.

Cruzel, Elise (2004): “'Passer à l'Attac': éléments pour l'analyse d'un engagement altermondialiste", Politix, 17 (68), pp. 135-163.

Darmon, Muriel (2003): Devenir anorexique, La Découverte, París.

Durkheim, Emile (1983): Les règles de la méthode sociologique, PUF (Quadrige), París.

Fretel, Julien (2004): Militants catholiques en politique, Tesis Doctoral de Ciencia Política, Universidad París I, disponible en sitio web del GEOPP: http://www.geopp.org (2004): "Le parti comme fabrique de notables", Politix, 17 (65), pp. 45-72.

(2004): "Quand des catholiques vont au parti", Actes de la Recherche en Sciences Sociales, 155, pp. 77-89.

(2005): "Quand la crise de la droite débouche sur la victoire de l'UMP. Éléments pour une réflexion sur les cycles politiques et électoraux et sur les effets de réalité de la croyance crisologique", en Frédérique Matonti (dir.): La démobilisation politique, La Dispute, París, pp. 37-67. 
Favre, Pierre (2005): Comprendre le monde pour le changer, Presses de Sciences Po, París.

Gaudin, Jean Pierre (2007): Gouverner par contrat, Presses des Sciences Po, París.

Gaxie, Daniel (1977): "Economie des partis et rétribution du militantisme", Revue Française de Science Politique, 27 (1), pp. 123-154.

(2005): "Rétributions du militantisme et paradoxes de l'action collective", Revue Suisse de Science Politique, 11 (1), pp. 157-188.

Ion, Jacques (1977): La fin des militants?, Éditions de l'Atelier, París.

(2005): Militer aujourd'hui, CEVIPOF/Autrement, París.

Katz, Richard y Peter Mair (1995): "Changing Models of Party Organization in Party Democracy", Party Politics, 1, pp. 5-28.

Lagroye, Jacques (2002): "L'institution en pratiques", Revue Suisse de Science Politique, 8 (3-4), pp. 114-128.

Lagroye, Jacques y Johanna Siméant (2003): "Gouvernement des humains et légitimation des institutions", en P. Favre, J. Hayward eY. Schemeil: Être gouverné. Etudes en I'honneur de Jean Leca, Presses de Sciences Po, París.

Lagroye, Jacques (2008): "Historicisation de la Science politique en France?", en Michel Offerlé y Henri Rousso: Histoire et Science politique, PUR, Rennes.

Lefebvre, Rémi (2004): “Je quitte le Parti socialiste tous les jours dans ma tête", comunicación en las jornadas de estudio "Vivre et militer dans les institutions", LASSP-Sciences Po, Toulouse.

Lefebvre, Rémi y Frédéric Sawicki (2006): La société des socialistes, Éditions du Croquant, París.

Michelat, Guy y Michel Simon (2004): Les ouvriers et la politique, Presses de Sciences Po, París.

Phélippeau, Eric (2002): L'invention de l'homme politique moderne, Belin (Socio-histoires), París.

Perrineau, Pascal (1994): L'engagement politique. Déclin ou mutation?, Presses de Sciences Po, París.

Pinçon, Michel y Monique Pinçon-Charlot (2007): Les ghettos du gotha, Seuil, París.

Pudal, Bernard (2002): "La beauté de la mort communiste", Revue Française de Science Politique, 52 (5-6), pp. 545-559.

Sawicki, Frédéric (1997): Les réseaux du Parti socialiste, Belin (Socio-Histoire), París.

Sirinelli, Jean-François (dir.) (2006): Histoire des droites, Gallimard (3 tomos), París.

Sorbets, Claude (1988): "Notables: quelques considérations sur l'usage de la notion", trabajo presentado en el Congreso de la Asociación Francesa de Ciencia Política: Les élites politiques locales, Burdeos, pp. 55-62.

Tudesq, André-Jean (1964): Les grands notables en France (1840-1849), PUF, París.

Ysmal, Colette (1989): Les partis politiques sous la $5^{\text {ème } R e ́ p u b l i q u e, ~ M o n t c h r e s t i e n, ~ P a r i ́ s . ~}$

Zunigo, Xavier (2003): Volontaires chez Mère Teresa. Auprès des plus pauvres d'entre les pauvres, Belin, col. Sociologiquement, París. 